\title{
The relationship between parental education and adolescents' soft drink intake from the age of 11-13 years, and possible mediating effects of availability and accessibility
}

\author{
Torunn H. Totland ${ }^{1 *}$, Nanna Lien ${ }^{1}$, Ingunn H. Bergh ${ }^{2}$, Mona Bjelland ${ }^{1}$, Mekdes K. Gebremariam ${ }^{1}$, \\ Knut-Inge Klepp ${ }^{1}$ and Lene F. Andersen ${ }^{1}$ \\ ${ }^{1}$ Department of Nutrition, University of Oslo, PO Box 1046 Blindern, NO-0316 Oslo, Norway \\ ${ }^{2}$ Department of Coaching and Psychology, Norwegian School of Sport Sciences, PO Box 4014, Ullevål Stadion, \\ NO-0806 Oslo, Norway
}

(Submitted 9 July 2012 - Final revision received 4 December 2012 - Accepted 4 December 2012 - First published online 4 February 2013)

\begin{abstract}
The present study examined the prospective relationship between parental education and adolescents' soft drink intake over 20 months, and possible mediating effects of adolescents' availability and accessibility of soft drinks at home. A total of 866 adolescents, with data on two time points in the Norwegian HEalth In Adolescents (HEIA) cohort study (2007-9), were included in the analyses. Data on intake and determinants of soft drinks were collected from adolescents and both parents by questionnaires. Mediation analyses using linear regression investigated the total and direct effects of parental education on adolescents' soft drink intake from the age of 11-13 years. In order to investigate prospective relationships, two models were set up to measure the (1) prediction and (2) change in consumption over 20 months. Possible mediation effects of availability and perceived accessibility at home were further examined in both models. The results showed that a lower level of parental education predicted a higher intake of soft drinks among adolescents after 20 months, and that higher perceived accessibility of soft drinks reported by adolescents and mothers explained $39 \%$ of the total effect. No relationship was observed between parental education and the change in adolescents' intake of soft drinks over 20 months. Interventions aimed at families with low parental education should target the perceived accessibility of soft drinks at home in order to diminish social differences in adolescents' soft drink consumption.
\end{abstract}

Key words: Sugar-sweetened beverages: Socio-economic position: Parental education: Adolescents: Mediation

Sugar-sweetened beverage consumption contributes to a considerable proportion of adolescents' energy intake ${ }^{(1-4)}$, and is one of the energy balance-related behaviours associated with overweight and weight gain among children and adolescents $^{(5-9)}$. The consumption of soft drinks is shown to track from childhood to adolescence ${ }^{(10)}$ and further into adult$\operatorname{hood}^{(11,12)}$. In order to support a healthy weight development, it is essential to identify factors in the environment that may influence energy balance-related behaviours ${ }^{(12-14)}$. Longitudinal studies are currently needed in order to identify possible environmental determinants ${ }^{(15,16)}$.

The home food environment is considered to be of importance in the development of children's and adolescents' dietary behaviours $^{(7,12,17,18)}$. Parents are found to play an important role in shaping the dietary behaviours of their children by determining which foods are available and how foods are prepared in the home ${ }^{(7,12)}$. Parental education is one aspect of the home environment, and a lower level of parental education has been found to be associated with poorer diets ${ }^{(12,19)}$, and with an increased prevalence of overweight and obesity ${ }^{(12,20)}$ among adolescents. Cross-sectional studies have furthermore reported an inverse association between parental education and adolescents' soft drink consumption ${ }^{(21-23)}$; however, no studies have to our knowledge investigated this relationship longitudinally.

The relationship between parental education and dietary behaviours (e.g. consumption of soft drinks) may be explained through determinants in the home environment ${ }^{(24)}$, but this has not been much studied. Parental education has been inversely associated with children's and adolescents' availability and accessibility of soft drinks at home $23,25,26)$. Moreover, a recent review reported a positive relationship between the availability of soft drinks at home and consumption among adolescents aged $10-12$ years ${ }^{(27)}$, but

Abbreviations: HEIA, HEalth In Adolescents; $M_{1}$, availability; $M_{2}$, perceived accessibility by adolescents; $M_{3}$, perceived accessibility by mothers; $M_{4}$, perceived accessibility by fathers; T0, baseline survey; T2, 20 months' follow-up.

*Corresponding author: T. H. Totland, fax +47228515 31, email t.h.totland@medisin.uio.no 
only one study was found to investigate this relationship longitudinally ${ }^{(28)}$. Less is known about the association between the accessibility of soft drinks at home and adolescents' intake $^{(18)}$.

Further understanding of whether availability and accessibility influence the prospective relationship between parental education and adolescents' soft drink consumption through mediating pathways is important to be able to modify this behaviour. The present study hypothesised that lower parental education is associated with an increased intake of soft drinks among adolescents from the age of 11-13 years, and that this relationship is mediated by higher availability and perceived accessibility of soft drinks at home.

\section{Methods \\ Subjects and study design}

Data were obtained from the HEalth In Adolescents (HEIA) cohort study, consisting of participants from the twenty-five control schools included in the HEIA intervention study. The design and methodology have been described in detail elsewhere ${ }^{(29)}$. All sixth graders were invited to take part in the study, resulting in a HEIA cohort of 1381 adolescents. At the baseline survey (T0) in September 2007, 975 (71\%) adolescents participated. In May 2008, 970 (70\%) participants attended the first follow-up, and 945 (68\%) adolescents participated in the 20 months' follow-up (T2) during May 2009. Parents or legal guardians (hereafter called parents) of the adolescents were also asked to participate in the study at T0 and T2. For the purpose of the present study, only participants attending T0 and T2, with data on parental education at T0 and adolescents' soft drink intake at T2, were included, resulting in $89 \%$ of the adolescents participating at T0 (866/975).

The present study was conducted according to the guidelines laid down in the Declaration of Helsinki, and all procedures were approved by the Regional Committee for Medical Research Ethics and the Norwegian Social Science Data Service. Written informed consent was obtained from the parents of all participants.

\section{Data collection}

Information on the educational level of both parents was collected from the parents through the consent forms for their child. Internet-based questionnaires were filled in by the adolescents during school hours at all time points, taking about $45 \mathrm{~min}$ to complete. The questionnaires assessed dietary, sedentary and physical activity behaviours and their determinants. Trained staff was available during data collection, collecting anthropometric measurements at T0 and T2. Adolescents brought home paper questionnaires to each of the parents, who returned them through their adolescents and the school to the HEIA project workers. Mothers and fathers answered the same questions assessing dietary, sedentary and physical activity behaviours, their determinants and presumed determinants of their child's dietary and physical activity behaviours at $\mathrm{T} 0$ and $\mathrm{T} 2$. Additional questions on the availability of foods in the home were measured at T0 among mothers only. All questionnaires consisted of mostly pre-coded answer categories.

\section{Dietary behaviour}

Usual consumption of carbonated sugar-sweetened soft drinks (hereafter called soft drinks) was reported by the adolescents, by frequency per weekday in six categories ranging from never/seldom to every weekday, and amount in glasses for each occasion in four categories ranging from one glass to four glasses or more. For weekends, the consumption was measured by the total number of glasses over both days in eight categories ranging from never/seldom to seven glasses or more. Instructions in the questionnaire specified that $5 \mathrm{dl}$ beverage equalled three glasses, making one glass $1.67 \mathrm{dl}$. The intake of soft drinks was therefore calculated into $\mathrm{dl} /$ week from the sum of five weekdays and two weekend days. A separate test-retest study among 114 sixth graders, from the same sampling area as the main study, was conducted before baseline data collection ${ }^{(23,29)}$. The selfreported measures of soft drinks obtained good test-retest reliability (Spearman's $\rho$ : $0 \cdot 73$, data not shown).

\section{Determinants}

Parental education was dichotomised into categories of 12 years or less and 13 years or more (university or college attendance). Educational level of the parent with the longest education was used, or else the one available. Age- and sex-specific BMI cut-off values, as proposed by the International Obesity Task Force ${ }^{(30)}$, were used to categorise the adolescents into normal weight or overweight/obese based on objectively measured height and weight.

Home availability of soft drinks was determined by mothers with the question 'Do you have soft drinks available in your house at this moment?', with answer categories yes or no. Adolescents' perceived accessibility of soft drinks in the home was determined by adolescents and each parent with the question: 'When soft drinks with sugar are available at home, can you (your child) serve yourself (him-/herself) as you (he/she) please(s)?' The six pre-coded answer categories were as follows: always, most days, sometimes, seldom or never serve as pleased and not available at home. Measures of adolescents' availability and perceived accessibility of soft drinks obtained good test-retest reliability (Spearman's $\rho: 0 \cdot 61-0 \cdot 71$, data not shown).

\section{Data analysis}

All statistical analyses were performed by IBM $^{\circledR}$ SPSS $^{\circledR}$ Statistics, version 19.0 (IBM Corporation). Attrition analysis was calculated between participants in the included sample ( $n$ 866) and those lost to follow-up between T0 and T2 ( $n$ 109), using independent-samples $t$ tests for continuous variables and Pearson's $\chi^{2}$ tests for categorical variables. Additional missing values appeared when data from adolescents, mothers and fathers were combined in the 


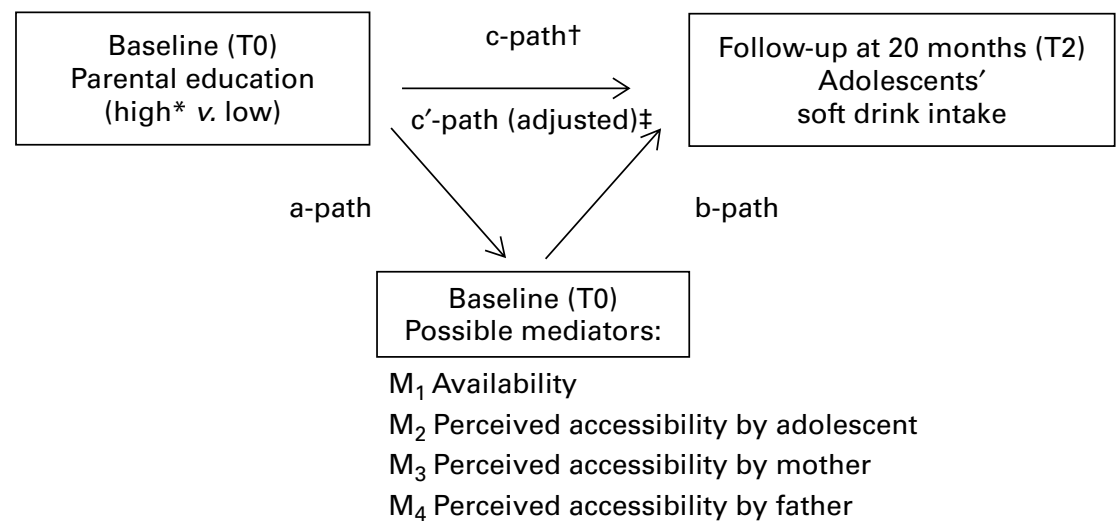

Fig. 1. Prediction of parental education on adolescents’ soft drink intake after 20 months (model 1). * Reference group. $†$ Adjusted for sex. $¥$ Adjusted for sex and potential mediator(s)

mediation analyses. Attrition analysis was for this reason also conducted on the differences between the mediation sample ( $n$ 557) and those with incomplete data ( $n$ 418). Independent-samples $t$ tests and Pearson's $\chi^{2}$ tests were further used to investigate differences in adolescents' intake, availability and perceived accessibility of soft drinks by parental education at both time points. Pearson's correlation coefficients were obtained in order to investigate correlations between possible mediating variables of home availability and perceived accessibility measured by adolescents, mothers and fathers.

In order to examine prospective relationships, two models were set up to measure the influence of parental education on adolescents' soft drink intake over a time period of 20 months (Figs. 1 and 2). Model 1 (Fig. 1) investigated the prediction of parental education at T0 on adolescents' soft drink intake at T2. Model 2 (Fig. 2) investigated the relationship between parental education at T0 and the change in adolescents' soft drink intake over 20 months. Change in adolescents' soft drink intake between the time points was calculated by absolute change scores. Absolute change scores measure unconditional changes over time ${ }^{(31,32)}$, and are calculated by the difference score between the time points $(\mathrm{T} 2-\mathrm{T} 0)^{(31-33)}$.
According to MacKinnon et al. ${ }^{(34)}$, a mediator is a variable that transmits the effect of an independent variable on a dependent variable. Adolescents' availability $\left(M_{1}\right)$ and perceived accessibility of soft drinks measured by adolescents $\left(\mathrm{M}_{2}\right)$, mothers $\left(\mathrm{M}_{3}\right)$ and fathers $\left(\mathrm{M}_{4}\right)$ at T0 were examined as possible mediating variables in both models. All analyses were adjusted for sex. Adolescents' weight status was found to be a confounder of the results in model 2 , and was therefore adjusted for in this model. The possible clustering by schools was tested using linear mixed model analyses. Only $4 \%$ of the unexplained variance of adolescents' soft drink intake was found at the school level in model 1 and $1 \%$ was found in model 2 (data not shown), and therefore multilevel analyses were not performed ${ }^{(35)}$. Mediation analyses were performed using linear regression, and unstandardised $\beta$ coefficients are presented. Assumptions for the mediation analyses were met in both models.

Single mediation analyses were calculated by three steps: (1) the c-path measures the total effect of parental education on adolescents' prospective soft drink intake (model 1) and the change in adolescents' soft drink intake over 20 months (model 2); (2) the a-path measures the relationship of parental education with each of the possible mediators $\left(M_{1}-M_{4}\right)$ in

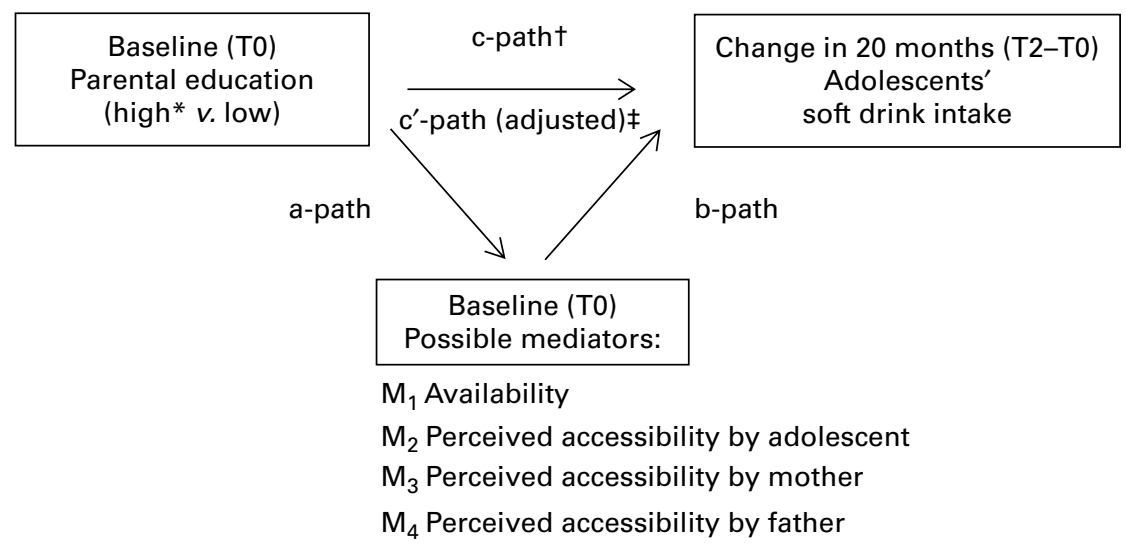

Fig. 2. Relationship between parental education on the change in adolescents' soft drink intake over 20 months (model 2 ). ${ }^{\star}$ Reference group. † Adjusted for sex and weight status (based on the International Obesity Task Force cut-off points). $¥$ Adjusted for sex, weight status and potential mediator(s). 
Table 1. Participant characteristics at baseline and attrition analyses of the included sample $(n 866)$ and the mediation sample $(n 557)$

(Mean values and standard deviations)

\begin{tabular}{|c|c|c|c|c|c|c|c|c|c|c|c|c|c|c|}
\hline \multirow[b]{3}{*}{ Measurements } & \multicolumn{7}{|c|}{ Total sample } & \multicolumn{7}{|c|}{ Mediation sample } \\
\hline & \multicolumn{3}{|c|}{ Included } & \multicolumn{3}{|c|}{ Excluded } & \multirow[b]{2}{*}{$P^{*}$} & \multicolumn{3}{|c|}{ Included } & \multicolumn{3}{|c|}{ Missing } & \multirow[b]{2}{*}{$P^{*}$} \\
\hline & $n$ & Mean & SD & $n$ & Mean & SD & & $n$ & Mean & SD & $n$ & Mean & SD & \\
\hline Sex & 866 & & & 109 & & & 0.485 & 557 & & & 418 & & & $0 \cdot 118$ \\
\hline \% Boys & & 51.5 & & & $55 \cdot 0$ & & & & $54 \cdot 8$ & & & $49 \cdot 7$ & & \\
\hline $\begin{array}{l}\text { Parental education } † \\
\% \text { Low }\end{array}$ & 866 & $30 \cdot 9$ & & 79 & $44 \cdot 3$ & & 0.015 & 557 & $26 \cdot 0$ & & 388 & $40 \cdot 7$ & & $<0.001$ \\
\hline Age (years) & 866 & $11 \cdot 2$ & 0.3 & 109 & $11 \cdot 2$ & 0.3 & 0.758 & 557 & $11 \cdot 2$ & 0.3 & 418 & $11 \cdot 2$ & 0.3 & 0.243 \\
\hline Soft drink intake (dl/week) & 839 & $5 \cdot 3$ & $5 \cdot 8$ & 103 & $5 \cdot 6$ & $5 \cdot 8$ & 0.522 & 557 & $5 \cdot 2$ & $5 \cdot 9$ & 385 & $5 \cdot 5$ & $5 \cdot 8$ & 0.406 \\
\hline Availability & 702 & & & 73 & & & 0.337 & 557 & & & 218 & & & 0.049 \\
\hline$\%$ No & & 61.4 & & & $67 \cdot 1$ & & & & $59 \cdot 8$ & & & $67 \cdot 4$ & & \\
\hline $\begin{array}{l}\text { Perceived accessibility by } \\
\text { adolescents } \ddagger\end{array}$ & 862 & 1.9 & $1 \cdot 1$ & 107 & 1.9 & $1 \cdot 2$ & 0.553 & 557 & $1 \cdot 8$ & $1 \cdot 2$ & 412 & 1.9 & $1 \cdot 1$ & 0.441 \\
\hline Perceived accessibility by mothers $\ddagger$ & 708 & 1.5 & 1.1 & 72 & 1.7 & 1.2 & 0.394 & 557 & 1.5 & $1 \cdot 1$ & 223 & 1.6 & $1 \cdot 1$ & 0.195 \\
\hline Perceived accessibility by fathers $\ddagger$ & 603 & $1 \cdot 8$ & $1 \cdot 1$ & 54 & 1.6 & 1.4 & 0.503 & 557 & $1 \cdot 8$ & $1 \cdot 1$ & 100 & $1 \cdot 8$ & $1 \cdot 2$ & 0.945 \\
\hline
\end{tabular}

${ }^{*}$ Attrition analysis by independent-samples $t$ test/Pearson's $\chi^{2}$ test.

$\dagger$ Parental education as low $v$. high (university/college).

$\ddagger$ Perceived accessibility measured by six answer categories; from not available at home (recoded as 0 ) to always served as pleased (recoded as 5 ).

both models; (3) the b-path measures the relationship between each of the possible mediators $\left(\mathrm{M}_{1}-\mathrm{M}_{4}\right)$ on adolescents' prospective soft drink intake (model 1) and the change in adolescents' soft drink intake over 20 months (model 2), when adjusted for parental education ${ }^{(34,36)}$ (Figs. 1 and 2). The mediation effect $(\mathrm{a} \times \mathrm{b})$ with $95 \% \mathrm{CI}$ and statistical significance was obtained from bootstrapping, calculated by resampling of 1000 independent samples using the SPSS script described by Preacher \& Hayes ${ }^{(36)}$. A multiple mediation analysis was finally conducted for each model, by calculating the a-path and b-path when adjusted for all significant mediating variables of availability and perceived accessibility from the single mediation analyses. A fourth step was then calculated: (4) the $c^{\prime}$-path measures the direct effect of parental education on adolescents' prospective soft drink intake (model 1) and the change in adolescents' soft drink intake over 20 months (model 2), when adjusted for all significant mediating variables of availability and perceived accessibility from the single mediation analyses ${ }^{(34,36)}$.
Mediation effects with 95\% CI and statistical significance by bootstrapping were finally conducted ${ }^{(36)}$.

\section{Results}

Of the 866 participants included in these analyses, 51.5\% were boys and the mean age was $11 \cdot 2$ years at T0 (Table 1 ). A total of $30.9 \%$ of the adolescents had parents with lower education, which was significantly less than among those lost to follow-up ( $n$ 109; Table 1 ). No other significant differences in adolescents' sex, age, intake of soft drinks or availability and perceived accessibility of soft drinks were found in the attrition analysis of participants lost to follow-up. Similar findings were seen in the attrition analysis of the adolescents with complete data in the mediation analysis $v$. those with incomplete data ( $n$ 418; Table 1 ).

The mean intake, availability and perceived accessibility of soft drinks at T0 and T2 by parental education are shown in Table 2. Adolescents with parents of low education consumed significantly more soft drinks at both time points than those of

Table 2. Adolescents' intake, availability and perceived accessibility of soft drinks (dl/week) at age 11 (T0) and age 13 (T2) years by parental education (Mean values and standard deviations)

\begin{tabular}{|c|c|c|c|c|c|c|c|c|c|c|c|c|c|c|}
\hline \multirow[b]{4}{*}{ Adolescents' measurements } & \multicolumn{7}{|c|}{ T0 } & \multicolumn{7}{|c|}{ T2 } \\
\hline & \multicolumn{7}{|c|}{ Parental education* } & \multicolumn{7}{|c|}{ Parental education* } \\
\hline & \multicolumn{3}{|c|}{ Low } & \multicolumn{3}{|c|}{ High } & \multirow[b]{2}{*}{$P \dagger$} & \multicolumn{3}{|c|}{ Low } & \multicolumn{3}{|c|}{ High } & \multirow[b]{2}{*}{$P \dagger$} \\
\hline & $n$ & Mean & SD & $n$ & Mean & SD & & $n$ & Mean & SD & $n$ & Mean & SD & \\
\hline Soft drink intake by adolescents & 258 & $6 \cdot 7$ & $7 \cdot 0$ & 581 & 4.6 & $5 \cdot 1$ & $<0.001$ & 268 & $7 \cdot 6$ & $7 \cdot 4$ & 598 & 5.4 & $5 \cdot 8$ & $<0.001$ \\
\hline Availability & 203 & 0.4 & 0.5 & 499 & 0.4 & 0.5 & 0.455 & 177 & 0.5 & 0.5 & 433 & 0.4 & 0.5 & 0.055 \\
\hline $\begin{array}{l}\text { Perceived accessibility by } \\
\text { adolescents } \ddagger\end{array}$ & 265 & $2 \cdot 1$ & $1 \cdot 1$ & 597 & $1 \cdot 8$ & $1 \cdot 1$ & $<0.001$ & 267 & $2 \cdot 3$ & $2 \cdot 3$ & 598 & 1.9 & $1 \cdot 3$ & $<0.001$ \\
\hline Perceived accessibility by mothers $\ddagger$ & 202 & 1.7 & $1 \cdot 2$ & 506 & 1.5 & $1 \cdot 1$ & 0.003 & 184 & 1.8 & $1 \cdot 1$ & 438 & 1.6 & $1 \cdot 1$ & 0.062 \\
\hline Perceived accessibility by fathers $\ddagger$ & 163 & $2 \cdot 0$ & $1 \cdot 1$ & 440 & 1.7 & $1 \cdot 1$ & $<0.001$ & 133 & $2 \cdot 2$ & $1 \cdot 3$ & 383 & 1.9 & $1 \cdot 2$ & 0.027 \\
\hline
\end{tabular}

* Parental education as low $v$. high (university/college).

† Difference between the groups of parental education with independent-samples $t$ test/Pearson's $\chi^{2}$ test.

$\ddagger$ Perceived accessibility measured by six answer categories; from not available at home (recoded as 0 ) to always served as pleased (recoded as 5 ). 
Table 3. Correlations between the measures of adolescents' availability and perceived accessibility of soft drinks as reported by 11 -year-olds and their parents

\begin{tabular}{cccccc}
\hline & $n$ & $\mathrm{M}_{1}$ & $\mathrm{M}_{2}$ & $\mathrm{M}_{3}$ & $\mathrm{M}_{4}$ \\
\hline $\mathrm{M}_{1}$ & 702 & 1 & & & \\
$\mathrm{M}_{2}$ & 862 & $0.11^{\star}$ & 1 & & \\
$\mathrm{M}_{3}$ & 708 & $0.28^{\star}$ & $0.35^{\star}$ & 1 & \\
$\mathrm{M}_{4}$ & 603 & $0.25^{\star}$ & $0.25^{\star}$ & $0.47^{\star}$ & 1 \\
\hline
\end{tabular}

$M_{1}$, availability; $M_{2}$, perceived accessibility by adolescents; $M_{3}$, perceived accessibility by mothers; $\mathrm{M}_{4}$, perceived accessibility by fathers.

*Pearson's correlation coefficients were significant $(P<0.05)$.

parents with high education. Perceived accessibility was also significantly higher among adolescents with parents of low education at T0 and T2. However, associations were not found for adolescents' availability of soft drinks (Table 2). Pearson's correlations between the possible mediating variables of availability and perceived accessibility at T0 were $<0.5$ (Table 3). The largest correlation $(r 0.47)$ was found between the perceived accessibility of soft drinks reported by mothers and fathers.

\section{Model 1: parental education predicting adolescents' soft drink intake after 20 months}

Single mediation analyses showed a significant total effect between parental education and adolescents' soft drink intake after 20 months (c-path), where low parental education at T0 indicated a higher intake of soft drinks at T2 (Table 4). The multiple mediation analysis additionally showed a significant direct effect ( $c^{\prime}$-path) of parental education on adolescents' soft drink intake after 20 months, indicating that this relationship was still present after adjusting for significant mediators of the relationship.

Single mediation analyses found significant mediation effects of adolescents' perceived accessibility of soft drinks reported by adolescents, mothers and fathers on the relationship between parental education at T0 and soft drink intake at T2. No mediation effect was found for the availability of soft drinks in the home. The multiple mediation analysis showed significant mediation effects of adolescents' perceived accessibility of soft drinks reported by adolescents and mothers by explaining 39\% of the total effect, but a mediation effect was no longer found for perceived accessibility reported by fathers.

Strong relationships between parental education and the perceived accessibility of soft drinks measured by adolescents, mothers and fathers were furthermore observed in single mediation analyses (a-path), but this relationship was not significant for the availability of soft drinks at home. Significant associations were furthermore observed for the availability and perceived accessibility of soft drinks at T0 on adolescents' consumption at $\mathrm{T} 2$, in single mediation analyses (b-path).

\section{Model 2: parental education predicting the change in adolescents' soft drink intake over 20 months}

No significant relationship was found between parental education at T0 and the change in adolescents' soft drink intake over 20 months (T2 - T0) in single mediation analyses (c-path) (Table 5). The multiple mediation analysis was not performed in model 2, because no significant mediating effects of availability or perceived accessibility in the home were detected in the single mediation analyses.

\section{Discussion}

The present study found that the level of parental education is inversely associated with adolescents' soft drink intake at both ages of 11 and 13 years. Furthermore, single mediation analyses indicated that parental education predicts adolescents' soft drink intake between the ages of 11 and 13 years (c-path). Other studies investigating the prediction of parental education on adolescents' soft drink consumption were not found; however, the result is consistent with a recent cross-sectional study among Norwegian sixth and seventh graders $^{(22)}$. The multiple mediation analysis furthermore observed a significant direct effect between parental education and adolescents' prospective soft drink intake after 20 months ( $c^{\prime}$-path). Hence, this relationship does not seem to be fully mediated by the availability or perceived accessibility of soft drinks in the home.

Table 4. Prediction of parental educationt on adolescents' soft drink intake after 20 months (T2), and the possible mediating effects of availability and perceived accessibility at baseline (T0) $(n 557)$

\begin{tabular}{|c|c|c|c|c|c|c|c|c|c|c|c|}
\hline Measurements & c-path & SE & a-path & SE & b-path & SE & $c^{\prime}$-path & SE & $a \times b \neq$ & $95 \% \mathrm{Cl}$ & $a \times b / c \S$ \\
\hline Single mediation models $\|$ & $1.9^{*}$ & 0.6 & & & & & & & & & \\
\hline $\mathrm{M}_{1}$ & & & 0.0 & 0.0 & $1 \cdot 6^{\star}$ & 0.5 & & & -0.1 & $-0.2,0.1$ & \\
\hline $\mathrm{M}_{2}$ & & & $0.4^{*}$ & $0 \cdot 1$ & $1 \cdot 6^{\star \star}$ & 0.2 & & & 0.6 & $0 \cdot 2,1 \cdot 1$ & $29 \%$ \\
\hline$M_{3}$ & & & $0 \cdot 3^{\star}$ & 0.1 & $1.4^{\star \star}$ & 0.2 & & & 0.4 & $0.2,0.9$ & $23 \%$ \\
\hline $\mathrm{M}_{4}$ & & & $0 \cdot 4^{\star *}$ & $0 \cdot 1$ & $0.7^{\star}$ & 0.2 & & & 0.3 & $0.0,0.5$ & $14 \%$ \\
\hline Multiple mediation model|| & $1.9^{*}$ & 0.6 & & & & & $1 \cdot 2^{\star}$ & $0 \cdot 6$ & 0.7 & $0.3,1 \cdot 3$ & $39 \%$ \\
\hline $\mathrm{M}_{2}$ & & & $0.4^{*}$ & $0 \cdot 1$ & $1 \cdot 3^{\star \star}$ & 0.2 & & & 0.5 & $0.2,0.9$ & $24 \%$ \\
\hline$M_{3}$ & & & $0.3^{*}$ & $0 \cdot 1$ & $0.9^{*}$ & 0.3 & & & 0.3 & $0.1,0.6$ & $15 \%$ \\
\hline$M_{4}$ & & & $0.4^{\star \star}$ & 0.1 & 0.0 & 0.3 & & & 0.0 & $-0.3,0.2$ & \\
\hline
\end{tabular}

$M_{1}$, availability; $M_{2}$, perceived accessibility by adolescents; $M_{3}$, perceived accessibility by mothers; $M_{4}$, perceived accessibility by fathers.

Statistical significance: ${ }^{\star} P<0.05,{ }^{\star \star} P<0.001$.

†Baseline (T0) parental education as high (university/college) $v$. low.

$\ddagger$ Mediation effect.

$\S$ Percentage mediation effect.

|| Linear regression analysis, adjusted for sex. 
Table 5. Relationship between parental educationt and the change in adolescents' soft drink intake over 20 months (T2 - T0), and the possible mediating effects of availability and perceived accessibility at baseline (T0) $(n 550)$

\begin{tabular}{|c|c|c|c|c|c|c|c|c|}
\hline Measurements & c-path & SE & a-path & SE & b-path & SE & $a \times b \neq$ & $95 \% \mathrm{Cl}$ \\
\hline Single mediation models§ & -0.9 & 0.6 & & & & & & \\
\hline$M_{1}$ & & & 0.0 & 0.0 & -0.2 & 0.5 & 0.0 & $-0.0,0.2$ \\
\hline$M_{2}$ & & & $0.4^{*}$ & 0.1 & -0.3 & 0.2 & -0.1 & $-0.4,0.1$ \\
\hline$M_{3}$ & & & $0 \cdot 3^{\star}$ & 0.1 & 0.3 & 0.2 & 0.1 & $-0.1,0.3$ \\
\hline $\mathrm{M}_{4}$ & & & $0.4^{\star \star}$ & 0.1 & $0 \cdot 1$ & $0 \cdot 2$ & $0 \cdot 0$ & $-0.2,0.2$ \\
\hline
\end{tabular}

$M_{1}$, availability; $M_{2}$, perceived accessibility by adolescents; $M_{3}$, perceived accessibility by mothers; $M_{4}$, perceived accessibility by fathers.

Statistical significance: * $P<0.05,{ }^{\star \star} P<0.001$.

† Baseline (T0) parental education as high (university/college) $v$. low.

$\ddagger$ Mediation effect.

$\S$ Linear regression analysis, adjusted for sex and weight status (normal/overweight)

Adolescents' perceived accessibility of soft drinks at the age of 11 years reported by adolescents and mothers partly mediated the prospective relationship between parental education and adolescents' soft drink intake after 20 months, by explaining $39 \%$ of the total effect in the multiple mediation analysis. Perceived accessibility of soft drinks reported by fathers was no longer a significant mediator, when adjusted for perceived accessibility measured by adolescents and mothers. A correlation was found between parental reports of perceived accessibility ( $r 0.47)$, and caution should therefore be made before disregarding the importance of perceived accessibility of soft drinks reported by fathers. Availability of soft drinks in the home was neither a mediator of the total effect between parental education and adolescents' prospective soft drink intake after 20 months, possibly explained by small differences in the availability of soft drinks between the levels of parental education among the 11-year-olds. However, it is important to mention that availability was measured by only one question on whether soft drinks were available in the home or not, which may not capture all dimensions of adolescents' soft drink availability. The results are somewhat consistent with a recent cross-sectional study among preschool children in Belgium, showing that the relationship between parental education and the consumption of soft drinks was almost entirely mediated by accessibility at the dinner table, availability in the home and permissiveness ${ }^{(26)}$. Other personal or environmental mediating variables may also be involved, but this was not tested in the present analyses. Perceived accessibility measured by adolescents and parents may be important determinants to consider in interventions aiming to reduce differences by parental education in adolescents' prospective soft drink consumption.

Single mediation analyses found both availability and perceived accessibility among adolescents and parents to be strong predictors of adolescents' soft drink intake after 20 months, when adjusted for sex and parental education (b-path). Several cross-sectional studies have observed a positive association between adolescents' self-reported home availability of soft drinks and consumption ${ }^{(37-39)}$, when adjusted for sex $^{(38)}$, age $\mathrm{e}^{(37)}$, ethnicity and school level ${ }^{(39)}$. Norwegian cross-sectional data have also found perceived accessibility measured by adolescents themselves to be correlated with soft drink intake among nine and tenth graders, when adjusted for sex, educational plans, dieting, grade and school level ${ }^{(18)}$. Correlations between adolescents' and parents' reports of perceived accessibility were low in the present study, indicating that adolescents' perception of their food environment is not necessarily the same as that of their parents, which has also been reported by others ${ }^{(13,17,23,40)}$.

No association was seen between parental education and the change in adolescents' soft drink intake over 20 months. This may indicate that differences by parental education in adolescents' soft drink intake were established before this age and did not increase between the ages of 11 and 13 years. Further on, no relationship was observed between parental education and availability or perceived accessibility or between availability or perceived accessibility and the change in soft drink intake over time. Hence, availability of soft drinks did not mediate the effect of parental education on the change in adolescents' soft drink intake from the age of 11-13 years. These findings are not consistent with those of Ezendam et $a l .{ }^{(28)}$, who found that self-reported perceived availability of soft drinks at home was associated with the change in adolescents' soft drink intake over 4 months. The association was partly mediated through adolescents' perceived behaviour control. However, the adolescents were slightly older at baseline (mean age 12.6 years) ${ }^{(28)}$, and changes may be more rapid later in adolescence. More studies should therefore investigate this relationship.

These results should be viewed in light of some limitations of the study. Although the participation rate of sampled schools was low (21\%), attrition analyses showed that there was no significant difference between schools that participated in the study and schools that declined participation in terms of the number of students in the sixth grade and overall size $^{(41)}$. Attrition analysis disclosed significant differences in the level of parental education between those included and excluded from these analyses. However, no significant differences were seen in the intake or availability of soft drinks at home, thus we believe that the results are representative for this population of 11-13-year-olds. The use of absolute change scores may be a problem because the measure does not take into account the phenomena of regression towards the mean ${ }^{(33)}$. Unconditional change over time was measured because differences in adolescents' soft drink intake were observed between the levels of parental education at baseline ${ }^{(31,32)}$. Furthermore, the correlation between soft drink measurements at T0 and T2 was $<0.5$ in the present study (data not shown), which is considered to give acceptable reliability of absolute change scores ${ }^{(32)}$. 
The strengths of the present study were the longitudinal study design based on a relatively large sample size at a narrow age range, with a high participation rate over time. Moreover, the questionnaire obtained moderate-to-high test-retest correlations, indicating the reliability of the measures ${ }^{(29)}$. The question measuring soft drink consumption used in the HEIA questionnaire has previously been validated in another study within the same age group ${ }^{(42)}$, although the HEIA study asked for intake on weekdays and weekends separately. Information on parental education was for this purpose collected from the parents through the adolescents' consent forms, which is considered to give more reliable measurements than when collected from the adolescents themselves.

\section{Conclusion}

The present study showed that parental education predicts young adolescents' soft drink consumption after 20 months when adjusted for sex, and a significant direct effect was observed after adjusting for mediating variables of home availability and perceived accessibility. Thus, the hypothesis was to a certain extent supported, as we found that perceived accessibility of soft drinks partly mediated this relationship when measured by adolescents and mothers. Interventions aiming at families with low parental education should target both adolescents' and parents' perceived accessibility of soft drinks in order to reduce social differences in adolescents' soft drink consumption. Finally, the availability of soft drinks at home should in general be targeted to prevent the increase in adolescents' prospective intake.

\section{Acknowledgements}

The present study was supported by the Norwegian Extra Foundation for Health and Rehabilitation through the National Association of Public Health. The HEIA study was originally funded by the Norwegian Research Council (grant no. $15,5323 /$ V50) with supplementary funds from the Throne Holst Nutrition Research Foundation, the University of Oslo and the Norwegian School of Sport Sciences. We would like to thank $\varnothing$. Skare for statistical guidance, as well as all the participants and project staff who took part in this study. T. H. T. drafted the first manuscript, conducted the statistical analyses and revised the paper based on the comments by the other coauthors. N. L., I. H. B., M. B., K.-I. K. and L. F. A. participated in designing the study, project planning and/or data collection. All authors critically read and revised the paper, and approved the final version of the manuscript. T. H. T., N. L., I. H. B., M. B., M. K. G., K.-I. K. and L. F. A. declare that there are no conflicts of interest.

\section{References}

1. Briefel RR \& Johnson CL (2004) Secular trends in dietary intake in the United States. Annu Rev Nutr 24, 401-431.

2. Somerset SM (2003) Refined sugar intake in Australian children. Public Health Nutr 6, 809-813.
3. Duffey KJ, Huybrechts I, Mouratidou T, et al. (2012) Beverage consumption among European adolescents in the HELENA study. Eur J Clin Nutr 66, 244-252.

4. Overby NC, Lillegaard IT, Johansson L, et al. (2004) High intake of added sugar among Norwegian children and adolescents. Public Health Nutr 7, 285-293.

5. World Health Organization (2003) Diet, Nutrition and the Prevention of Chronic Diseases. Report of a Joint WHO/ FAO Expert Consultation. WHO Technical Report Series no. 916. Geneva: WHO.

6. World Cancer Research Fund \& American Institute for Cancer Research (2007) Food, Nutrition, Physical Activity, and the Prevention of Cancer: a Global Perspective. Washington, DC: AICR

7. Swinburn BA, Caterson I, Seidell JC, et al. (2004) Diet, nutrition and the prevention of excess weight gain and obesity. Public Health Nutr 7, 123-146.

8. Harrington S (2008) The role of sugar-sweetened beverage consumption in adolescent obesity: a review of the literature. J Sch Nurs 24, 3-12.

9. de Ruyter JC, Olthof MR, Seidell JC, et al. (2012) A trial of sugar-free or sugar-sweetened beverages and body weight in children. $N$ Engl J Med 367, 1397-1406.

10. Totland TH, Gebremariam MK, Lien N, et al. (2012) Does tracking of dietary behaviours differ by parental education in children during the transition into adolescence? Public Health Nutr (epublication ahead of print version 9 July 2012).

11. Kvaavik E, Andersen LF \& Klepp KI (2005) The stability of soft drinks intake from adolescence to adult age and the association between long-term consumption of soft drinks and lifestyle factors and body weight. Public Health Nutr 8, $149-157$.

12. Larson N \& Story M (2009) A review of environmental influences on food choices. Ann Behav Med 38, Suppl. 1, S56-S73.

13. Swinburn B, Egger G \& Raza F (1999) Dissecting obesogenic environments: the development and application of a framework for identifying and prioritizing environmental interventions for obesity. Prev Med 29, 563-570.

14. Kremers SP, de Bruijn GJ, Visscher TL, et al. (2006) Environmental influences on energy balance-related behaviors: a dual-process view. Int J Behav Nutr Phys Act 3, 9.

15. Brug J, Kremers SP, Lenthe F, et al. (2008) Environmental determinants of healthy eating: in need of theory and evidence. Proc Nutr Soc 67, 307-316.

16. Van Der Horst K, Oenema A, Ferreira I, et al. (2007) A systematic review of environmental correlates of obesityrelated dietary behaviors in youth. Health Educ Res 22 , 203-226.

17. Rosenkranz RR \& Dzewaltowski DA (2008) Model of the home food environment pertaining to childhood obesity. Nutr Rev 66, 123-140.

18. Bere E, Glomnes ES, te Velde SJ, et al. (2008) Determinants of adolescents' soft drink consumption. Public Health Nutr 11, 49-56.

19. Hanson MD \& Chen E (2007) Socioeconomic status and health behaviors in adolescence: a review of the literature. J Behav Med 30, 263-285.

20. Shrewsbury V \& Wardle J (2008) Socioeconomic status and adiposity in childhood: a systematic review of cross-sectional studies 1990-2005. Obesity (Silver Spring) 16, 275-284.

21. Brug J, van Stralen MM, te Velde SJ, et al. (2012) Differences in weight status and energy-balance related behaviors among schoolchildren across Europe: the ENERGY-Project. PLoS One 7, e34742. 
22. Stea TH, Overby NC, Klepp KI, et al. (2011) Changes in beverage consumption in Norwegian children from 2001 to 2008. Public Health Nutr 15, 1-7.

23. Bjelland M, Lien N, Grydeland M, et al. (2011) Intakes and perceived home availability of sugar-sweetened beverages, fruit and vegetables as reported by mothers, fathers and adolescents in the HEIA (HEalth In Adolescents) study. Public Health Nutr 14, 2156-2165.

24. de Vet E, de Ridder DT \& de Wit JB (2011) Environmental correlates of physical activity and dietary behaviours among young people: a systematic review of reviews. Obes Rev 12, e130-e142.

25. Macfarlane A, Crawford D, Ball K, et al. (2007) Adolescent home food environments and socioeconomic position. Asia Pac J Clin Nutr 16, 748-756.

26. de Coen V, Vansteelandt S, Maes L, et al. (2012) Parental socioeconomic status and soft drink consumption of the child. The mediating proportion of parenting practices. Appetite 59, 76-80.

27. Verloigne M, Van LW, Maes L, et al. (2012) Family- and school-based correlates of energy balance-related behaviours in 10-12-year-old children: a systematic review within the ENERGY (EuropeaN Energy balance Research to prevent excessive weight Gain among Youth) project. Public Health Nutr 15, 1380-1395.

28. Ezendam NP, Evans AE, Stigler MH, et al. (2010) Cognitive and home environmental predictors of change in sugarsweetened beverage consumption among adolescents. $\mathrm{Br} \mathrm{J}$ Nutr 103, 768-774.

29. Lien N, Bjelland M, Bergh IH, et al. (2010) Design of a 20-month comprehensive, multicomponent school-based randomised trial to promote healthy weight development among 11-13 year olds: The HEalth In Adolescents study. Scand J Public Health 38, 38-51.

30. Cole TJ, Bellizzi MC, Flegal KM, et al. (2000) Establishing a standard definition for child overweight and obesity worldwide: international survey. BMJ 320, 1240-1243.
31. Fitzmaurice G (2001) A conundrum in the analysis of change. Nutrition 17, 360-361.

32. MacKinnon DP (2008) Introduction to Statistical Mediation Analysis. New York: Psychology Press.

33. Twisk JWR (2007) Applied Longitudinal Data Analysis for Epidemiology - A Practical Guide, 4th ed. Cambridge: Cambridge University Press.

34. Mackinnon DP, Fairchild AJ \& Fritz MS (2007) Mediation analysis. Annu Rev Psychol 58, 593-614.

35. Heck RH, Thomas SL \& Tabata LN (2010) Multilevel and Longitudinal Modeling with IBM SPSS. New York: Routledge.

36. Preacher KJ \& Hayes AF (2008) Asymptotic and resampling strategies for assessing and comparing indirect effects in multiple mediator models. Behav Res Methods 40, 879-891.

37. Denney-Wilson E, Crawford D, Dobbins T, et al. (2009) Influences on consumption of soft drinks and fast foods in adolescents. Asia Pac J Clin Nutr 18, 447-452.

38. Grimm GC, Harnack L \& Story M (2004) Factors associated with soft drink consumption in school-aged children. $J \mathrm{Am}$ Diet Assoc 104, 1244-1249.

39. Tak NI, te Velde SJ, Oenema A, et al. (2011) The association between home environmental variables and soft drink consumption among adolescents. Exploration of mediation by individual cognitions and habit strength. Appetite $\mathbf{5 6}$ 503-510.

40. Reinaerts E, de Nooijer NJ \& De Vries NK (2007) Parental versus child reporting of fruit and vegetable consumption. Int J Behav Nutr Phys Act 4, 33.

41. Gebremariam MK, Andersen LF, Bjelland M, et al. (2012) Does the school food environment influence the dietary behaviours of Norwegian 11-year-olds? The HEIA study. Scand J Public Health 40, 491-497.

42. Lillegaard IT, Overby NC \& Andersen LF (2012) Evaluation of a short food frequency questionnaire used among Norwegian children. Food Nutr Res 56 (Epublication 16 January 2012). 